\title{
A Case Study of the Economic Impact of Seasonal Visitors to a Lake Watershed Environment
}

\author{
By Michael Donihue* \\ Sahan T. M. Dissanayake \\ Lucy O'Keeffe
}

\begin{abstract}
Ecosystem services generated by lake watershed environments can be important drivers of local and regional economic activity. In this analysis we use expenditure data collected from a survey of 445 seasonal visitors and year-round residents in a unique lake watershed environment to estimate their impact on the region's economy. Our survey and research methods were designed to explore social and economic dimensions of the area as well as capture information on spending, income, and general knowledge of tourists to the region about the health of the lakes in the watershed. Using an Impact Analysis for Planning (IMPLAN) modeling framework, we quantify the direct, indirect and induced effects of spending by tourists in the watershed. We find an estimated annual impact of \$6.8 million in spending, including multiplier effects, and support for 68 full and part-time jobs in the watershed. Our hope is that this information will help to better inform decisions by policy makers, developers, land use planners, and stakeholder groups about the effects of ecosystem services and conservation land-use practices on tourism and trade.
\end{abstract}

Keywords: Economic impact analysis, Ecosystem services, Lake Watershed, Tourism

\section{Introduction}

The Belgrade Lakes Watershed is located in the United States in Central Maine and is composed of seven interconnected lakes that together form a dynamic socio-ecological system. A watershed refers to the land from which water flows into a particular water body. As one of Maine's unique destinations for four-season recreation and tourism, there exists a tight interconnection between human activity in the Watershed and the quality of the lakes. The Belgrade Lakes Watershed covers 29,067 acres (45.4 square miles) and includes the towns of Belgrade, Rome, Mercer and Smithfield. This lakes region developed as a summer community in the late nineteenth century in the context of a growing trend for outdoors vacationing in the United States (Burgess and Nelson 2009). Tourists come from all over to enjoy the unspoiled beauty of these lakes, and enjoy fishing, camping, boating, hiking, golf and other activities. The area also supports a wide variety of local businesses

\footnotetext{
* Professor, Colby College, USA.

${ }^{\dagger}$ Assistant Professor, Colby College, USA.

${ }^{\ddagger}$ Student, Colby College, USA.
} 
related to the lakes such as dining, lodging, and retail. The summer home culture combined with a deep sense of place among people in this region make the Belgrade Lakes Watershed a vibrant center for summer tourism.

Figure 1. Belgrade Lakes

Source: Google Maps.

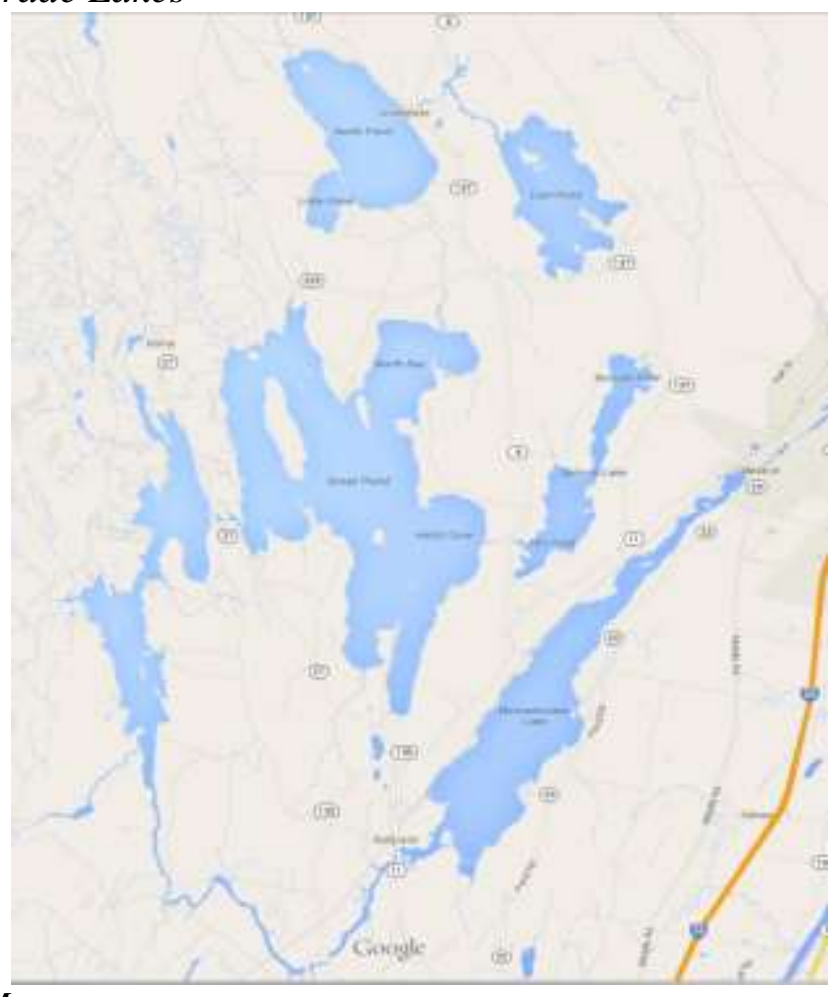

However, in recent years the Belgrade Lakes have been listed on Maine's list of water bodies most at risk from development. Burgess and Nelson (2009: 15) provides a perspective on the tight interconnection between the economic and environmental dimensions of this area.

"The environmental consequences resulting from the increased development of the Watershed are tightly linked to the economic reasons for sustaining the summer community in the Belgrades... A drop in tourism would negatively affect the town economically, for those who do have small business in the area cater mainly to summer people, and a small amount of local residents."

This study examines the economic impact of year-round and seasonal residents of the Belgrade Lakes Watershed. The analysis is based on 445 household surveys conducted in 2013. The surveys asked the amount of money homeowners and renters spend on food and dining, outdoor recreational activities, property maintenance and other relevant areas of household consumption. Additionally, this survey captured information on the 
demographics of year-round residents and seasonal visitors of the Watershed and their awareness of environmental issues in the region.

When interpreting this study's findings it is important to note that an economic impact assessment is only one measure of value, and many critical attributes of environmental resources cannot be easily monetized into this type of modeling. While expenditure data alone does not fully capture the total value of natural resources in a specific area, it does provide critical insight into how money gets distributed and the value that is generated by businesses tied to the ecosystem services provided by the resource. Therefore, an economic impact analysis can provide policy-relevant information that can help communities determine appropriate policies to balance economic development as well as conservation goals. For the Belgrade Lakes Watershed, the results of this economic impact study may be used to inform legislation to implement economic development and conservation policies that will continue to sustain this unique lake environment and in particular underscore the value of tourism to the communities. Further information related to household demographics and knowledge of lake-related issues may help lake associations, and trusts, conservation alliances, and other stakeholder groups better target their community outreach and awareness initiatives.

\section{Economic Impact Analysis}

Input-output analysis is a common tool that has been applied in numerous economic impact studies to assess the value of different environmental and natural resource based environments as well as economic development opportunities more generally (Bergstrom and Cordell 1990, Cline and Seidl 2010, Xie 2012). This form of analysis is especially useful in describing current and potential contributions of outdoor recreational activities to the local economy. Impact Analysis for Planning (IMPLAN) is a widely used input-output modeling software program originally developed through a collaborative effort between researchers at the University of Minnesota and the USA. Forest Service Land Use Planning Unit that estimates the linkages between different sectors of the economy, and is able to assess the direct, indirect and induced effects produced from them.

Unlike traditional input-output models, IMPLAN is built using social accounting matrices (SAM), which can capture non-market transactions such as tax payments that can also be considered as an important source of monetary flows. SAMs can be utilized to measure the economic impact of specific sources of economic activity and their relative distribution in terms of the direct, indirect and induced effects. In this particular study, the SAM are being applied to estimate the economic impact of current spending in the Belgrade Lakes Watershed from seasonal visitors and year around residents. When applied in this form, they are referred to as a multiplier model, in that they reflect the region's unique economic structure and trade situation and consider how spending propagates (multiplies) through the economy. 
In essence we are employing a "follow the money" paradigm as we attempt to estimate the economic impacts of measurable expenditures by seasonal and year-round residents of the Belgrade Lakes Watershed. Using the IMPLAN framework we can estimate the total impact by calculating direct, indirect, and induced effects across our identified categories of spending (Table 1). The aggregate value of these three differentiated effects provides an estimate of the total economic impact of the expenditures that were captured in the survey of residents and tourists in the Belgrade Lakes Watershed.

Table 1. Measuring Economic Impacts

Direct effects are the impacts that occur as a result of changes in production and output in those sectors of the economy that are directly related to the influx of spending.

Indirect effects come from economic interactions among industrial sectors as a result of purchasing or supplying inputs from one sector to another.

Induced effects occur through the linkages between an affected sector of the economy and households based on labor supplied and wages paid in order to capture implicit relationships with respect to resulting changes in household spending. Induced effects on household consumption expenditures can be attributed to both the direct and indirect effects.

\section{Methods}

The primary database for this economic impact analysis of the Belgrade Lakes Watershed was constructed using data gathered from a comprehensive survey of expenditures distributed in-person and through USA post. The in-person surveys were conducted for a random sample of tourists encountered at the Maine Lakes Resource Center in the town of Belgrade Lakes, shoppers at the local farmers market, and patrons at the local general store. The town of Belgrade Lakes is one of the central hubs of economic activity for tourists in the Belgrade Lakes Watershed and as such provided a useful location for collecting information on the area.

Seasonal residents were targeted for the in-person survey and are defined for our purposes as individuals who either own or rent a seasonal home and do not live in the Watershed year-round. Data collection occurred during the summer of 2013 and our research team conducted a total of 89 in-person surveys. The first section of the survey contained questions used to profile seasonal visitors in terms of length of stay, number of years visiting the area, location of year-round and seasonal residences, educational status, household income, and connection to place. A second section of our survey collected information relating to household expenditures. These questions ranged from typical spending on food and dining to spending on various outdoor recreational activities. A final section included questions to assess public awareness of environmental issues affecting the seven lakes in the Belgrade Lakes Watershed. For our final analysis we extrapolated the number of person- 
weeks for the summer to infer a total of 349 seasonal visitors to the Watershed (for example if a seasonal visitor spent 2 weeks, we assume there were, on average, similar seasonal visitors for each two-week period through the summer tourist season).

We also mailed a more detailed version of our survey to a random sample of 2,053 households with physical addresses located within the Belgrade Lakes Watershed boundary. Using property tax records, we employed geographic information systems (GIS) methods to extract those addresses located within our study area to form a comprehensive mailing list from which we randomly selected households. We had an 18\% response rate, with 356 of the mailed surveys returned and useable for our modeling efforts. The mailed survey captured data on the spending behavior of both year-round and seasonal residents of the Watershed. This household survey included all of the same questions as the in-person survey, in addition to more extensive questions on spending patterns related to communication services, cable TV, heating, electricity, education, and healthcare.

\section{Results}

Figure 2 provides a summary of the annual household incomes of our survey respondents. The average household income for respondents with a primary address inside the Belgrade Lakes Watershed was $\$ 97,818$. The average household income of respondents that have a primary address outside of the Watershed was $\$ 136,975$. The majority of respondents $(58 \%)$ had a total annual household income of between $\$ 50,000$ and $\$ 150,000$.

Figure 2. Household Income of Survey Respondents

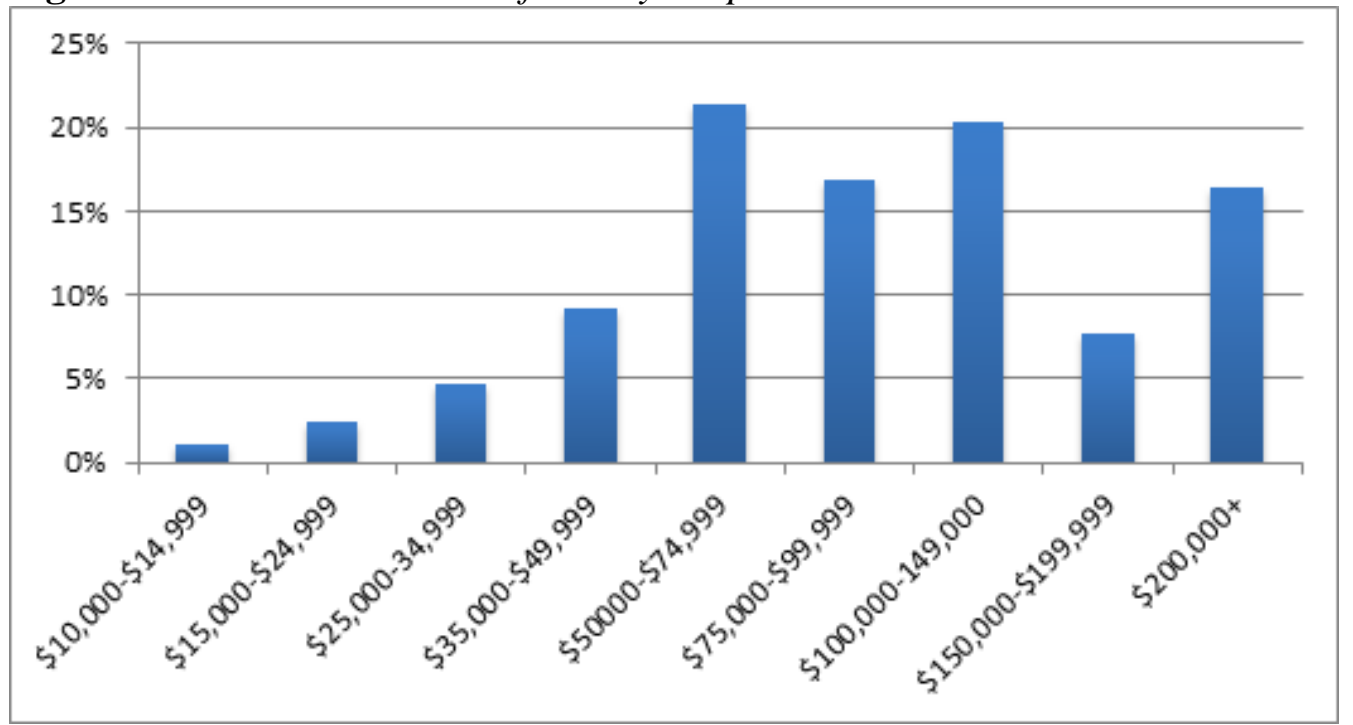

Source: Authors' calculations.

In terms of the education level of our respondents, Figure 3 displays the highest level of education achieved by members of their household. According 
to the results of our survey, $87 \%$ of survey respondents indicated having a member of their household with a college degree or higher.

Figure 3. Highest Level of Education Achieved by Member of Household

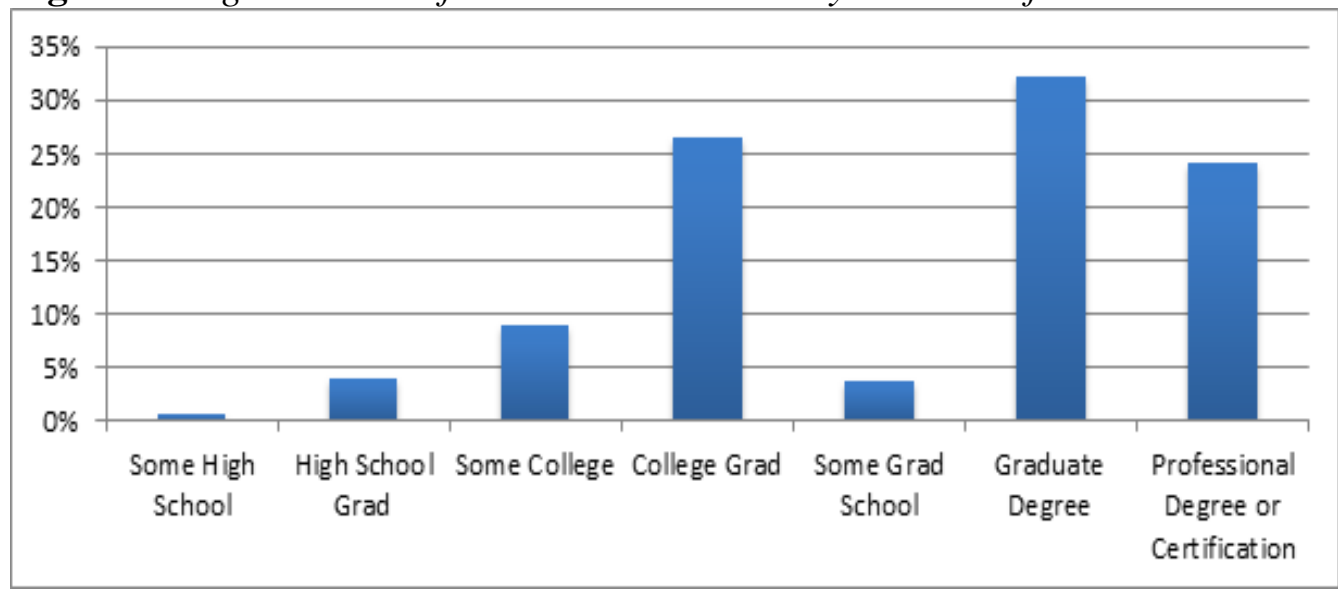

Source: Authors' calculations.

Figure 4 illustrates the geographic distribution of our survey respondents. Approximately $58 \%$ of the survey respondents were from New England. Florida (7\%) and New York (6\%) were also well-represented states of origin.

Figure 4. Geographic Distribution of Survey Respondents

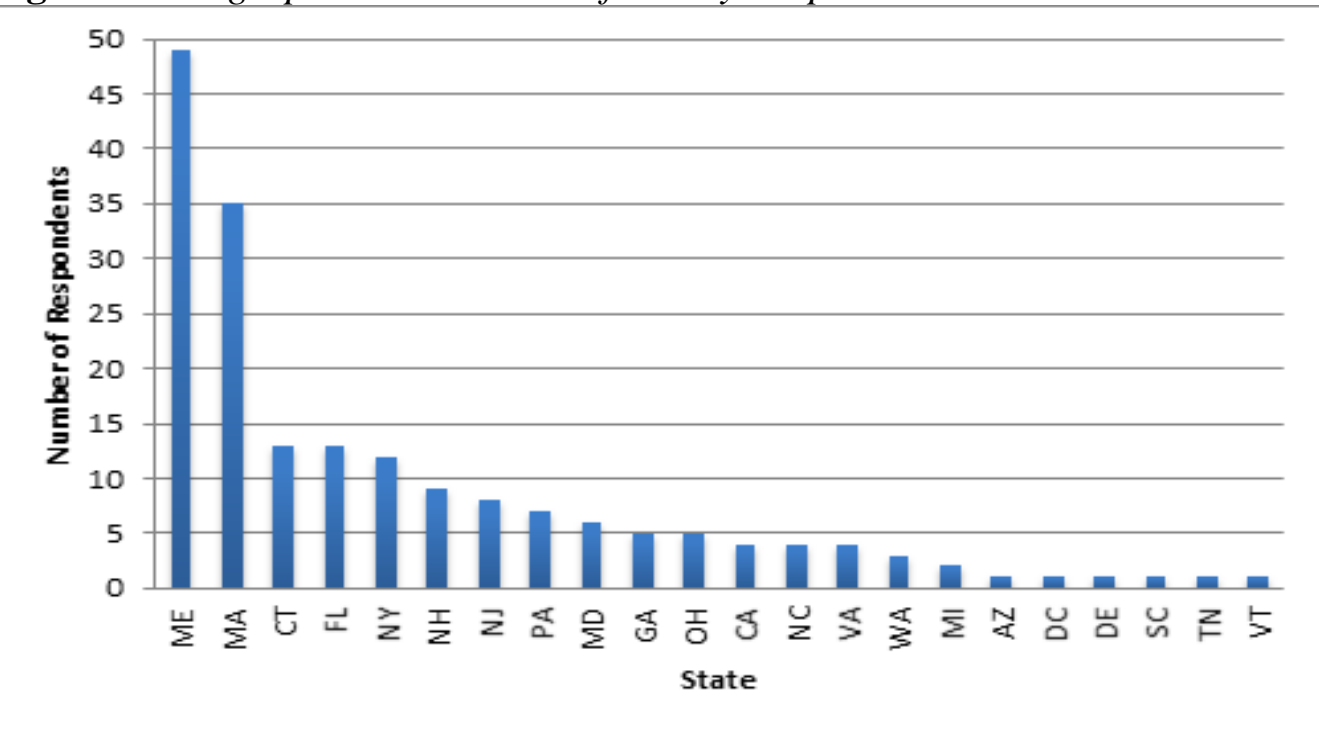

Source: Authors' calculations.

Table 2 details the distribution of the 356 returned mailed surveys in terms of the relative proportion that were completed from towns located in the Watershed or by households that own property in the Watershed, but live primarily outside of this region. The majority of mailed survey respondents (72\%) were from inside of the Belgrade Lakes Watershed. 
Table 2. Distribution of Responses from Mailed Household Survey

\begin{tabular}{|l|c|c|}
\hline Area & Respondents & Percent of Total \\
\hline Belgrade & 84 & $24 \%$ \\
\hline Belgrade Lakes & 14 & $4 \%$ \\
\hline Oakland & 70 & $20 \%$ \\
\hline Sidney & 48 & $13 \%$ \\
\hline Smithfield & 25 & $7 \%$ \\
\hline Other Towns & 14 & $4 \%$ \\
\hline Outside of Watershed & 101 & $28 \%$ \\
\hline Total & $\mathbf{3 5 6}$ & $\mathbf{1 0 0 \%}$ \\
\hline
\end{tabular}

Source: Authors' calculations.

Figure 5 highlights the distribution of reported spending on major outdoor recreational activities represented in the Belgrade Lakes Watershed. Not surprisingly, the majority of expenditures are related to motor boating, which is the most common activity in the area. Other areas where respondents indicated spending significant amounts of money included golfing, open water fishing, and souvenir and gift shops. These activities all have well-developed markets in the Watershed and, in general, there are a lot more expenditures associated with these activities. The major expenditures associated with motor boating, for example, included paying for storage, maintenance, fuel, and permits. In comparison, people do not have to pay for biking, hiking, or wildlife viewing, so survey respondents generally considered these activities as having little or no cost. In the survey, we recorded expenditures associated with these lower cost activities in terms of how much they pay for food and fuel during the time when they are participating in these activities.

Figure 5. Distribution of Spending on Outdoor Activities

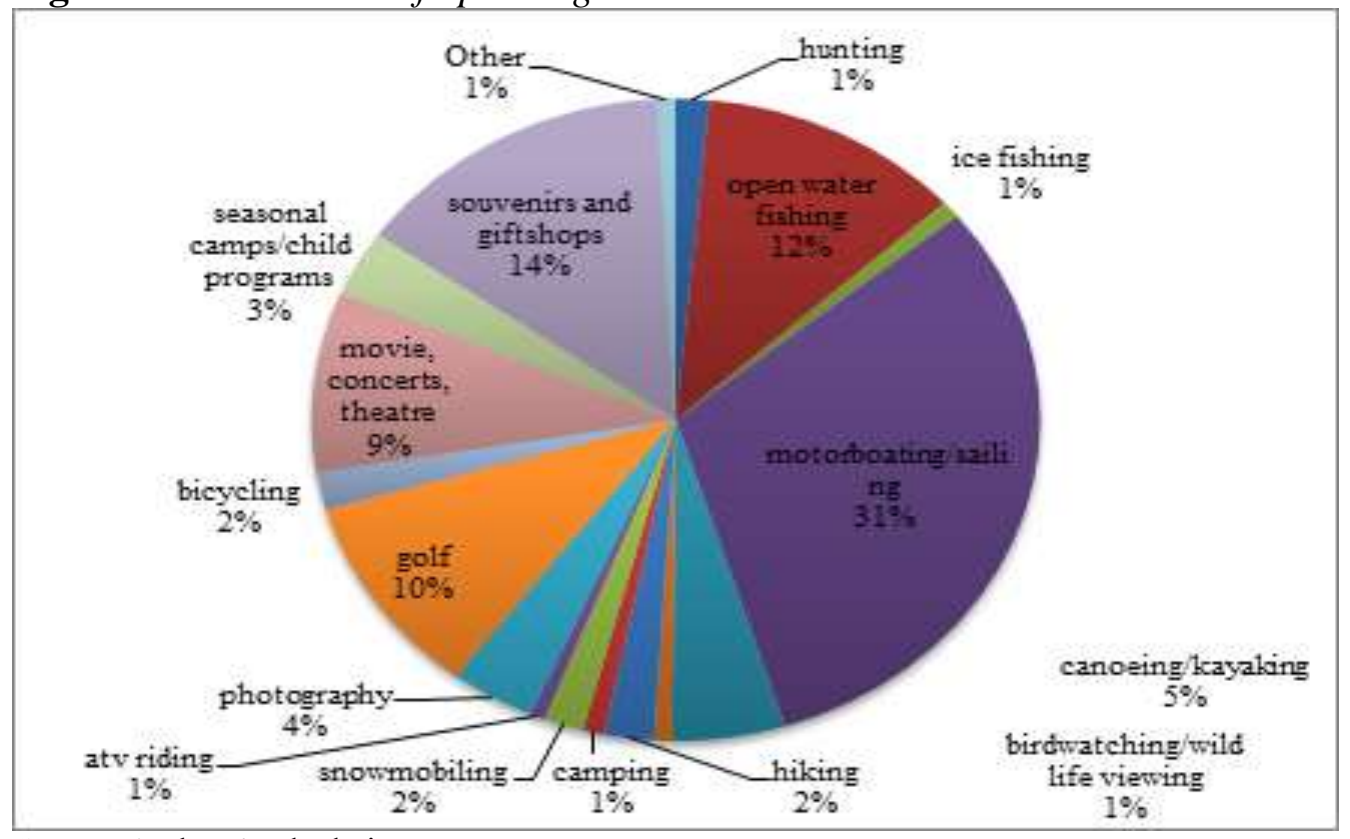

Source: Authors' calculations. 
Our analysis of the expenditure data collected through the in-person survey reveals interesting trends related to general spending behavior. Average expenditures by seasonal residents in this model were highest in the categories of property taxes, property maintenance, grocery shopping, and motor boating and sailing. Average spending on local food and average weekly rental fees are also high, indicating that these are major areas of spending for seasonal residents of the Watershed.

The total economic impact of the expenditures for 349 seasonal residents to the Watershed is estimated to be approximately $\$ 1.8$ million. Our results indicate that the expenditures generated by seasonal residents captured in our in-person model ultimately support 27.5 full and part-time jobs. Total output is the accumulation of total revenues and sales, or equivalently, the total value of the output generated from the direct and secondary effects of the initial economic stimulus. The total value added column in Table 3 shows the value of revenues generated from expenditures in the impacted industries. Labor income represents all sources of income, including wages and benefits and proprietor income that are produced as a result of the initial change in expenditures.

Table 3. Impact Results for the In-Person Survey Model

\begin{tabular}{|l|c|c|c|c|}
\hline Impact Type & Employment & Labor Income & $\begin{array}{c}\text { Total Value } \\
\text { Added }\end{array}$ & Output \\
\hline Direct Effect & 21.4 & $\$ 600,985$ & $\$ 1,009,343$ & $\$ 1,144,464$ \\
\hline Indirect Effect & 2.5 & $\$ 64,337$ & $\$ 118,405$ & $\$ 209,657$ \\
\hline Induced Effect & 3.6 & $\$ 139,865$ & $\$ 254,205$ & $\$ 415,972$ \\
\hline Total Effect & $\mathbf{2 7 . 5}$ & $\mathbf{\$ 8 0 5 , 1 8 7}$ & $\mathbf{\$ 1 , 3 8 1 , 9 5 3}$ & $\mathbf{\$ 1 , 7 7 0 , 0 9 3}$ \\
\hline
\end{tabular}

Source: Authors' calculations.

The results of our IMPLAN model also reveal the major industrial sectors that are affected by these expenditures in terms of output and employment. Not surprisingly, the largest impacted industries in the Belgrade Lakes Watershed include food and beverage retail stores, food service and drinking places, and real estate establishments. These results are consistent with the fact that much of the spending information collected in the survey was related to the food service industry. Also one of biggest sources of spending for seasonal visitors are rental fees, and those expenditures are allocated toward local real estate establishments and related industries. Personal and household goods repair and maintenance is another significantly impacted industry, which makes sense because seasonal residents invest in the upkeep of their properties.

We estimated the total economic impact of the expenditures generated by 705 seasonal and year-round residents of the Watershed to be approximately $\$ 6.8$ million (Table 4). These expenditures also support a total of 68 full and part-time jobs in this region. The combined impact of the aggregated spending behavior of both year-round and in-person survey respondents is substantially higher, because the sample size is twice that of the in-person sample, and the mailed survey includes more expenditure information. Because more 
household spending information is captured in this analysis it provides a more comprehensive assessment of the total economic value generated by the Watershed.

Table 4. Combined Impact from 705 Seasonal and Year-Round Residents

\begin{tabular}{|l|c|c|c|c|}
\hline Impact Type & Employment & Labor Income & Total Value Added & Output \\
\hline Direct Effect & 47.3 & $\$ 2,038,249$ & $\$ 2,831,482$ & $\$ 4,602,662$ \\
\hline Indirect Effect & 8.4 & $\$ 259,568$ & $\$ 458,995$ & $\$ 801,996$ \\
\hline Induced Effect & 12.5 & $\$ 483,623$ & $\$ 880,275$ & $\$ 1,440,075$ \\
\hline Total Effect & $\mathbf{6 8 . 2}$ & $\mathbf{\$ 2 , 7 8 1 , 4 4 0}$ & $\mathbf{\$ 4 , 1 7 0 , 7 5 2}$ & $\mathbf{\$ 6 , 8 4 4 , 7 3 4}$ \\
\hline
\end{tabular}

Source: Authors' calculations.

The most impacted industry in terms of both total employment and total output generated is the personal and household goods repair and maintenance industry. As previously mentioned, both the in-person and mailed surveys collected annual expenditure information pertaining to property maintenance and repairs, landscaping, and snowplowing. Other significantly impacted industries in the total expenditure model include food and beverage retail stores, food services and drinking places, as well dry-cleaning and laundry services. The mailed survey contained more detailed questions about spending on laundry, which is pertinent to a lot of seasonal camp owners that may not have the capability to do laundry at their camp. Real estate establishments are heavily impacted by spending on rental commissions and other associated fees. An additional set of economic sectors related to health care services are presented in the impact statement for the total model, a reflection of the health care spending information collected in the mailed survey.

\section{Conclusions}

Based on the results of our input-output analysis, it is evident that both year-round and seasonal residents of the Belgrade Lakes Watershed greatly contribute to the economy of the region. The total economic impact of the 705 households that we captured in our survey was $\$ 6.8$ million, including multiplier effects. The property maintenance and repair sector is the most impacted in terms of the total number of jobs and output generated by this economic activity. It is important to note that this figure is not a comprehensive assessment of the value of the Watershed, as the economic value of ecosystem services were not factored into this study. Other factors, such as real estate sales, charitable giving and philanthropic activity, and summer camp tuition are only indirectly accounted for in our analysis. Instead, this study provides a glimpse of the economic value that is generated by annual household expenditures of people who live or spend time in the Watershed. At this time we do not extrapolate from these results to infer the total economic impact from all visitors in the Belgrade Lakes Watershed or total economic impact state-wide in Maine from tourism. At the same time given the tens of thousands 
of visitors that arrive each year to enjoy the clean water, air and nature in Maine, the economic value of clean and healthy lakes are substantial.

The results of our demographic questionnaire highlight that both year-round and seasonal residents are deeply invested in this region based on family ties or how many years they have been visiting this area. Based on the consistent population of seasonal visitors, there is great potential to expand seasonal ventures that cater specifically to this population. In particular, regional planners may consider combining environmental conservation initiatives with expanded outdoor recreation activities in the Watershed. In addition, more private business can focus on sustainable landscaping, for example, which is increasingly becoming an important factor for homeowners.

The people that live in this area contribute to the inherent value of this region, and so it is important that the State of Maine provides the necessary resources to maintain the health of this fragile ecosystem. The Belgrade Lakes economy is deeply linked to its environment, which is why it so important that the health of the lakes is prioritized for the benefit of current and future generations.

More broadly, this paper offers a relatively straightforward approach to assessing a portion of the economic impact attributable to seasonal residents and visitors in an environmentally sensitive area. Our approach will likely have wider implications for small communities globally that are interested in sustainably developing areas for the ecosystem services they provide.

\section{Acknowledgments}

The data collection and analysis for this paper was completed during the 2013-14 academic year as part of Colby College's Modeling Resilience and Adaptation in the Belgrade Lakes Watershed project under the auspices of the University of Maine's Experimental Program to Stimulate Competitive Research (EPSCoR) grant, funded by the National Science Foundation, and the James W. Meehan Research and Internship fund established by Maura Shaughnessy for the Economics Department at Colby College. Under this project, Colby College students and faculty from the Departments of Chemistry, Geology, Economics, Biology; the Environmental Studies Program; and the Science, Technology, and Society Program collaborated with the Belgrade Regional Conservation Alliance, the Maine Lakes Society, five lake associations within the Belgrade Lakes Watershed, and faculty from the University of Maine system to form interdisciplinary teams with stakeholder participation to study the impacts of landscape and lake-ecosystem changes in this Belgrade Lakes region. This paper builds on work done in conjunction with an undergraduate honors thesis at Colby College by the student author ${ }^{1}$. The authors wish to acknowledge the helpful comments from two anonymous referees.

\footnotetext{
${ }^{1}$ See: O'Keeffe LG (2014) An Economic Impact Analysis of the Belgrade Lakes Watershed. Undergraduate Honors Thesis, Colby College. Retrieved from http://bit.ly/1Ke17nu.
} 


\section{References}

Bergstrom JC, Cordell H (1990) Economic impacts of recreational spending on rural areas: A case study. Economic Development Quarterly 4: 29-39.

Burgess IK, Nelson MK (2009) Belgrade Lakes, Maine: The History of a Summer Community and its Effect on the Environment (1774 - 2009).

Cline S, Seidl A (2010) Combining non-market valuation and input-output analysis for community tourism planning: Open space and water quality values in Colorado, USA. Economic Systems Research 22(4): 385-405.

Xie PF (2012) Socio-Economic Impacts of Birdwatching along Lake Erie: A Coastal Ohio Analysis. Ohio Sea Grant. Retrieved from http://bit.ly/1KPRxbF. 
